\title{
COMO O PROCESSO DE PRODUÇÃO DE MÍDIAS PODE CONTRIBUIR PARA A FORMAÇÃO DOCENTE?
}

Arianny de Sousa Lira: PGECM IFCE - Fortaleza, arianny_sousa@hotmail.com

Darlene Alves Leitão: UFC - Fortaleza, darlenealvesleitao@gmail.com

Juscileide Braga de Castro: UFC e PGECM IFCE - Fortaleza, juscileide@virtual.ufc.br

RESUMO: Este artigo tem como objetivo analisar o processo de construção do conhecimento dos docentes por meio da produção de recursos educacionais digitais, em uma oficina com o Scratch. A temática emerge sobre a importância da produção e da utilização de mídias e do desenvolvimento do pensamento computacional. A pesquisa teve abordagem metodológica qualitativa e analisou: registros escritos, fotográficos; transcrições e material produzido pelos participantes. Dentre as contribuições advindas do processo, destacam-se a percepção do processo vivenciado como uma metodologia a ser desenvolvida na escola; assim como, a possibilidade de dar ao professor o papel de autor de seu próprio material didático. A partir dos resultados, ressalta-se a importância da formação docente amparada na prática profissional.

Palavras-chaves: Tecnologias digitais. Construcionismo. Autoria. Formação docente.

\section{AS THE PROCESS OF MEDIA PRODUCTION CAN CONTRIBUTE TO TEACHER FORMATION?}

ABSTRACT: This article aims to analyze the process of building teachers' knowledge through the production of digital educational resources in a workshop with Scratch. The theme emerges about the importance of production and the use of media and the development of computational thinking. The research had qualitative methodological approach and analyzed: written, photographic records; transcripts and material produced by participants. Among the contributions coming from the process, we highlight the perception of the process experienced as a methodology to be developed in the school; as well as the possibility of giving the teacher the role of author of his own didactic material. From the results, the importance of the teacher training supported in the professional practice is emphasized.

Keywords: Digital technologies. Construccionismo. Authorship. Teacher formation.

\section{INTRODUÇÃO}

A sociedade está inserida em um contexto de submersão na era tecnológica, no qual as Tecnologias Digitais de Informação e Comunicação (TDIC) estão progressivamente presentes em nossas ações diárias. É importante frisar que esse contexto tecnológico transforma as relações sociais. Dentro do espaço educacional essa realidade não é diferente, pois a facilidade de acesso à informação vem alterando as formas de como as aprendizagens significativas vêm sendo desenvolvidas no âmbito escolar.

Papert (2008) considera e prevê que o futuro da Educação está entrelaçado ao avanço da cibernética. Relacionado ao conceito de comunicação e aos avanços tecnológicos, temos, segundo Chiavenato (2014), que a cibernética é uma ciência interdisciplinar que envolve comunicação e controle. A comunicação oferece sistemas de organização e de processamento de informações, tornando o sistema integrado e coerente, 
e o controle auxilia as demais ciências, regulando o comportamento, seja no animal (homem, seres vivos), ou seja, na máquina.

Com o avanço das tecnologias digitais as relações entre sujeitos e objetos se alteram, uma vez que podem modificar a percepção da realidade e a forma como se constrói conhecimento. Isto interfere na configuração cognitiva da manifestação do saber e da cultura.

Mudanças e rupturas culturais invadem a sociedade e chegam à escola. A Base Nacional Comum Curricular (BNCC) indica a utilização de tecnologias como: computadores, telefones celulares, tablets e afins, pois têm promovido mudanças sociais significativas na sociedade contemporânea.

Considerando o protagonismo, a cultura digital e a utilização de diferentes linguagens, preconizadas pela base, como competências importantes e necessárias para que sejam desenvolvidas na Educação Básica, as escolas podem explorar não apenas a utilização, mas a criação de tecnologias digitais (Brasil, 2017).

Papert (1980) foi um dos primeiros a defender que se pode aprender algo construindo um artefato, indicando que os computadores podem e devem ser utilizados para que as pessoas possam "pensar com” as máquinas e "pensar sobre” o próprio pensar. Este pesquisador propôs a programação Logo como forma de estimular "Powerful ideas" e "Procedural knowledge" (Papert, 1980).

Durante a criação de um artefato diferentes conhecimentos são mobilizados o que pode ajudar no desenvolvimento de habilidades e competências indicadas pela BNCC, assim como do pensamento computacional. Nesta perspectiva, pode-se correlacionar o pensamento computacional, definido por Brackmann (2017), como a capacidade crítica, criativa e estratégica de utilizar os fundamentos computacionais de forma individual ou colaborativa para resolver problemas em diversas áreas do conhecimento.

Contudo, propor atividades que considerem esta perspectiva não é uma tarefa fácil para o professor, pois requisita uma reanálise dos processos de ensino, o que requer a aproximação dos docentes com a cultura digital (Castro et al, 2017). Sendo assim, o momento cibernético atual torna necessário a realização de formações aos docentes a fim de potencializar os estudos acerca da criação de TDIC como atividade que pode ser desenvolvida na escola para a promoção da aprendizagem.

Diante deste contexto, o presente estudo tem como foco as contribuições dos processos de aprendizagem mediada pela tecnologia e tem os seguintes questionamentos norteadores: Como as TDIC podem ser utilizadas para a construção do conhecimento? Como o processo de criação de Recursos Educacionais Digitais (RED) auxiliaria na formação docente? A partir dessa problemática, têm-se como objetivo: analisar o processo de construção do conhecimento dos docentes ${ }^{1}$ por meio do uso de TDIC em uma oficina com o Scratch.

O estudo tem como referência as contribuições teóricas de Papert, aliado à temática que emerge sobre a importância da aquisição do pensamento computacional e do desenvolvimento de competências como a cultura digital, o protagonismo e a autoria.

Neste sentido, na próxima seção, discorre-se sobre as tecnologias digitais e a utilização desses recursos no processo de construção do conhecimento; o pensamento computacional auxiliando na criação de RED e as relações com as competências 4 e 5 propostas pela BNCC. Em seguida, apresenta-se a oficina com o Scratch e a análise realizada a partir das percepções dos participantes. Por fim, as considerações finais.

\section{AS TDIC E SUAS CONTRIBUIÇÕES NA FORMAÇÃO DOCENTE}

${ }^{1}$ A oficina teve como público-alvo docentes e estudantes da Licenciatura em Matemática e da Pedagogia 
A onipresença do uso das TDIC faz com que essa nova geração de crianças e de adolescentes que interagem, compartilham, usam e incorporam em sua rotina diária as tecnologias para navegar, pesquisar, postar vídeos e fotos, enviar mensagem, jogar, entre outras atividades, sofram mudanças em suas práticas sociais.

Os jovens estão imersos nessa cultura, enquanto que muitos professores, ainda que utilizem as TDIC em seu cotidiano, não compreendem e/ou não visualizam possibilidades pedagógicas para sua inserção na escola. Desta maneira optou-se por explorar as competências gerais 4 e 5 apresentadas na Base Nacional Comum Curricular BNCC (Brasil, 2017):

Competência 4: Utilizar diferentes linguagens - verbal (oral ou visual-motora, como Libras, e escrita), corporal, visual, sonora e digital -, bem como conhecimentos das linguagens artística, matemática e científica, para se expressar e partilhar informações, experiências, ideias e sentimentos em diferentes contextos e produzir sentidos que levem ao entendimento mútuo. Competência 5: Compreender, utilizar e criar tecnologias digitais de informação e comunicação de forma crítica, significativa, reflexiva e ética nas diversas práticas sociais (incluindo as escolares) para se comunicar, acessar e disseminar informações, produzir conhecimentos, resolver problemas e exercer protagonismo e autoria na vida pessoal e coletiva. (BRASIL, 2017, sn, grifo do autor)

Embora seja possível se utilizar diferentes abordagens metodológicas e recursos didáticos, as competências exploradas preveem a cultura digital nas escolas, seja para compreender, utilizar e/ou criar tecnologias digitais, como possibilidade de produzir informação e conhecimento. Nesse contexto, unindo tecnologia com a educação, percebese que essa perspectiva é algo fundamental na formação dos educadores (Brasil, 2017).

É importante ampliar a formação docente possibilitando que os professores vivenciem experiências ativas dentro da sua formação, permitindo que os mesmos estejam abertos e preparados para as novas mudanças metodológicas. As universidades proporcionam aos graduandos uma formação profissional em 'tempo pretérito', professores munidos de diplomas para trabalhar, porém, sem preparo para enfrentarem os tempos complexos e não lineares da atualidade (Demo, 2015).

Para Kenski (2012) é imprescindível que as escolas, sejam elas de Ensino Fundamental, Médio ou Superior, incorporem em sua prática e formação de seus cursos, esse movimento tecnológico ascendente, caso contrário, ficarão fadadas e condenadas à obsolescência. Assim, é necessário que as escolas e principalmente as universidades, explorem o uso de tecnologias na formação inicial de professores, assim como, compreendam e desenvolvam novas metodologias na sua abordagem.

No que diz respeito ao acesso à tecnologia, Garcia et al (2011, p. 81) explicam que os estudantes que "vivenciam durante seus processos de formação acadêmica momentos que podem fazer uso pedagógico das tecnologias, possuem maiores chances de compreender e utilizar futuramente tais tecnologias, sentindo-se mais seguros em relação ao seu uso”.

Ademais, vivência de práticas com abordagens metodológicas ativas, ou seja, centradas no aluno, podem possibilitar que os professores em formação conheçam abordagens diferentes daquelas nas quais a grande maioria foi formada. Sobre isso, Brito e Purificação (2012) evidenciam a importância da realização de práticas de ensino e de aprendizagem diferenciadas, de modo a proporcionar na formação inicial e continuada, o desenvolvimento de saberes profissionais, da criatividade e da reflexão do uso de artefatos tecnológicos. 
Dentre estas práticas destacam-se, neste trabalho, a aprendizagem baseada no construcionismo. Para o construcionismo a aprendizagem ocorre por meio da internalização de ações que acontecem quando o sujeito está conscientemente engajado em uma atividade (Papert, 2008).

Em uma pesquisa na formação inicial de professores que ensinam Matemática, Castro et al. (2017) basearam-se no construcionismo para realizar projeto que envolvia a produção colaborativa de mídias digitais. A abordagem metodológica considerou o Design Thinking ${ }^{2}$ para produzir 5 mídias que abordam conteúdos como: álgebra, medidas antropométricas, gráficos e situação de multiplicação. Para a produção das mídias foram utilizadas ferramentas como o Animaker, o Youtube, o Scratch, o editor de texto do Google Drive e o Power Point. A pesquisa apresenta evidências de que a abordagem construcionista, de aprender fazendo, contribuiu para a compreensão conceitual, teórica e metodológica dos conteúdos matemáticos trabalhados (Castro et al. 2017).

Ainda que a pesquisa de Castro et al. (2017) não tenha destacado os conceitos, as teorias e as metodologias aprendidas pelo grupo de estudantes da formação inicial em Pedagogia, constata-se o seu potencial na formação de Pedagogos que atuarão na Educação Básica. Além disso, verifica-se que para a construção das mídias houve a necessidade de instrumentalização de ferramentas de autoria, dentre elas o Scratch.

Assim como na pesquisa de Castro et al (2017), pretende-se utilizar o Scratch, por ser uma ferramenta que explora a programação em blocos que podem ser inseridos uns aos outros de forma única e seguindo uma lógica de programação. Segundo Brennan e Resnick (2012), atividades com o Scratch podem envolver o pensamento computacional em, pelo menos, três dimensões: [1] conceitos computacionais - ligados aos conceitos empregados na definição de programas; [2] práticas computacionais - relacionadas ao desenvolvimento de programas; e [3] perspectivas computacionais - associadas às perspectivas individuais e de mundo.

As atividades de programação com o Scratch podem explorar a criação de narrativas digitais, de jogos e de apresentações interativas. Ao criar/programar qualquer um destes materiais, o sujeito desenvolve a criatividade, os diferentes tipos de letramento, além de ampliar experiências práticas (Valente, 2016).

Cientes dessas possibilidades e da atual necessidade da sociedade, a BNCC apresenta a escola como um espaço plural e multicultural e, como tal, deve se pautar em um ensino justo e abrangente, assegurando aos estudantes desenvolvimentos de competências e habilidades no âmbito pedagógico. A seguir, detalhar-se-á os procedimentos metodológicos da investigação.

\section{PROCEDIMENTOS METODOLÓGICOS}

Descreve-se uma abordagem metodológica de natureza qualitativa, a partir da oficina "Desenvolvendo recursos digitais com o Scratch", realizada em dois dias presenciais, totalizando 10 horas. A oficina teve como objetivo a criação de RED com o intuito de permitir, por parte dos participantes, a construção de conceitos matemáticos atrelados ao uso de tecnologias digitais e a reflexão sobre as possibilidades de utilização desta abordagem em sua prática pedagógica.

A oficina foi realizada como parte das atividades do Projeto de Iniciação à Docência (PID) da Universidade Federal do Ceará (UFC). O público alvo era composto por 14 pessoas de diversos meios educacionais: estudantes do curso de Pedagogia e da

2 O Design Thinking consiste em uma abordagem de produção de mídias que contempla 4 etapas: (1) imersão; (2) análise e síntese; (3) ideação e (4) prototipação e testes (Castro et al 2017). 
Licenciatura em Matemática, professores da Educação Básica e alunos da Pós-Graduação Stricto Sensu em Educação.

Realizada no laboratório de Informática Educativa da Faculdade de Educação (FACED - UFC), as atividades do primeiro e segundo dia foram desenvolvidas de acordo com a sequência apresentada no Quadro 1, a seguir:

Quadro 1 - Metodologia da oficina

\begin{tabular}{|c|c|}
\hline \multicolumn{2}{|r|}{ ATIVIDADES DESENVOLVIDAS NA OFICINA } \\
\hline SEQUÊNCIA & DESCRIÇÃO \\
\hline $\begin{array}{c}1^{\circ} \text { DIA } \\
(3 \text { horas })\end{array}$ & $\begin{array}{l}\text { - Apresentação da ferramenta utilizada na oficina, como também das } \\
\text { possibilidades de criação, sites e recursos produzidos a partir do } \\
\text { Scratch. } \\
\text { - Sequências de atividades exploratórias no Scratch, envolvendo os } \\
\text { códigos de comando (instrumentalização da programação); } \\
\text { - Produção individual ou em dupla de um recurso voltado para o } \\
\text { ensino de Matemática. Nesta etapa, os participantes deveriam } \\
\text { escolher o conceito que seria abordado no recurso e sua apresentação. }\end{array}$ \\
\hline $\begin{array}{c}\text { Atividade à distância } \\
\text { (3 horas) }\end{array}$ & - Finalização das produções iniciadas no $1^{\circ}$ dia de oficina \\
\hline $\begin{array}{l}2^{\circ} \text { DIA } \\
\text { (3 horas e } 30 \\
\text { minutos) }\end{array}$ & $\begin{array}{l}\text { - Exposição das produções. Os participantes replicaram os recursos } \\
\text { produzidos, pontuando: o processo de construção, as aprendizagens } \\
\text { exploradas no RED, as dificuldades e as reflexões sobre o processo. } \\
\text { A cada apresentação os demais participantes deveriam compartilhar } \\
\text { as suas percepções como também sugestões e críticas. }\end{array}$ \\
\hline $\begin{array}{l}\text { Atividade à distância } \\
\text { (30 minutos) }\end{array}$ & $\begin{array}{l}\text { - Realização da avaliação final sobre a oficina, na qual os } \\
\text { participantes opinaram sobre as contribuições da oficina para a sua } \\
\text { formação docente. }\end{array}$ \\
\hline
\end{tabular}

Fonte: elaborado pelas autoras

As atividades envolviam um momento de explanação de conhecimentos iniciais sobre a linguagem de programação do Scratch, ferramenta utilizada nas produções dos RED. Deste modo, propiciou-se aos participantes um momento de apresentação das criações, bem como, as contribuições e sugestões dos participantes, oportunizando a troca de saberes e reflexões sobre as possíveis aplicações dos RED para a construção de conceitos matemáticos em sala de aula.

Os dados da pesquisa foram coletados a partir de observações realizadas durante a oficina por meio de registros escritos e fotográficos; gravações de áudios, e por meio do acesso aos RED produzidos pelos participantes. Também foram utilizadas as avaliações diagnósticas realizadas durante o período de inscrição e as respostas apresentadas na avaliação online aplicada após a oficina, que teve retorno de 7 participantes do grupo envolvido, auxiliando na análise dos resultados e oportunizando a chance de torná-los públicos. Os resultados deste trabalho são apresentados por meio de análises realizadas a partir dos dados coletados na oficina, e tendo como suporte o referencial teórico desenvolvido neste estudo.

\section{DISCUSSÃO DOS RESULTADOS}


Durante a oficina foram desenvolvidos 8 RED, conforme exposto no quadro 2, no qual foi detalhado o perfil dos participantes, o nome do RED produzido e o link de acesso às criações no site oficial ${ }^{3}$ do Scratch. O RED Uma aventura com Naruto: aprendendo com rãmen foi produzido por uma dupla e os demais foram produzidos individualmente. Instigado pelos questionamentos e reflexões da oficina, o participante do grupo 7 desenvolveu, após a oficina, outro RED denominado Pokémon e as operações.

Quadro 2-Recursos produzidos na oficina

\begin{tabular}{|c|c|c|c|}
\hline \multicolumn{4}{|c|}{ RED PRODUZIDOS A PARTIR DA OFICINA } \\
\hline GRUPO & FORMAÇÃO & NOME DO RED & LINK DE ACESSO \\
\hline 1 & $\begin{array}{l}\text { Professora da Educação } \\
\text { Básica, Licenciada em } \\
\text { Matemática }\end{array}$ & Operações matemáticas & $\frac{\text { https://scratch.mit.edu/p }}{\text { rojects/190318257/ }}$ \\
\hline 2 & $\begin{array}{l}\text { Mestranda em Educação, } \\
\text { Licenciada em Pedagogia }\end{array}$ & SPAECE & $\frac{\text { https://scratch.mit.edu/p }}{\text { rojects/188850354/ }}$ \\
\hline 3 & $\begin{array}{c}\text { Dupla - Graduandas em } \\
\text { Licenciatura em Matemática }\end{array}$ & $\begin{array}{c}\text { Uma aventura } \\
\text { com Naruto: } \\
\text { aprendendo com Rãmen }\end{array}$ & $\frac{\text { https://scratch.mit.edu/p }}{\underline{\text { rojects/190023355/ }}}$ \\
\hline 4 & Mestranda em Educação & Tentativa 1 & $\frac{\text { https://scratch.mit.edu/p }}{\text { rojects/190323543/ }}$ \\
\hline 5 & $\begin{array}{c}\text { Graduanda em Licenciatura } \\
\text { em Pedagogia }\end{array}$ & $\begin{array}{l}\text { Movimento e } \\
\text { velocidade }\end{array}$ & $\frac{\text { https://scratch.mit.edu/p }}{\text { rojects/190385679/ }}$ \\
\hline 6 & $\begin{array}{c}\text { Graduando em Licenciatura } \\
\text { em Matemática }\end{array}$ & Situação problema & não foi compartilhado \\
\hline \multirow[t]{2}{*}{7} & \multirow{2}{*}{$\begin{array}{c}\text { Graduando em Licenciatura } \\
\text { em Pedagogia }\end{array}$} & Jogo da multiplicação & $\frac{\underline{\text { htps://scratch.mit.edu/p }}}{\underline{\text { rojects/188684663/ }}}$ \\
\hline & & $\begin{array}{l}\text { Pokémon e as } \\
\text { operações }\end{array}$ & $\frac{\text { https://scratch.mit.edu/p }}{\text { rojects/190457492/ }}$ \\
\hline
\end{tabular}

Fonte: elaborado pelas autoras

Dos 14 participantes envolvidos, 8 participaram ativamente do processo de criação de RED; 3 participantes não produziram RED, mas, agregaram informações, compartilhando experiências desenvolvidas antes da oficina; e 3 participantes ausentaram-se no segundo dia de aplicação, não apresentando seus RED.

O grupo 6 não teve o recurso compartilhado, devido a problemas com a conta de e-mail do participante. Cursando Licenciatura em Matemática, e estando na faixa etária de 60 anos, o participante apresentou dificuldades relacionadas ao uso de aparatos tecnológicos digitais durante o processo de programação, porém prontificou-se a aprender, conseguindo desenvolver e apresentar o seu RED. O mesmo foi possível diante de uma dinâmica colaborativa, no qual o participante teve um apoio no segundo dia da oficina presencial. Percebe-se que o participante pôde apropriar-se tecnologicamente por meio da utilização da ferramenta Scratch, agregando a sua formação outros letramentos

${ }^{3}$ Link de acesso ao site oficial do Scratch: https://scratch.mit.edu/ 
antes não aprofundados, como o letramento digital, demonstrando um novo posicionamento diante do uso de tecnologias.

Para Arruda e Castro-Filho (2018), há uma necessidade de aquisição do letramento digital e do acesso às TDIC, pois percebe-se que essa apropriação proporciona habilidades ao docente para usar, processar e transformar a informação, por meio da conectividade, tendo como preceito a inclusão digital.

Em relação a formação continuada, um participante nos relatou que "[...] a participação na oficina apresenta à formação docente um recurso com infinitas possibilidades de desenvolver atividades pedagógicas na escola, tendo o professor como produtor de atividades e não apenas como reprodutor.” Nessa direção, observa-se a importância de trabalhar colocando os alunos enquanto protagonistas da aprendizagem, promovendo reflexão e autonomia, e propiciando aulas participativas, em que todos podem manipular e realizar descobertas.

Percebeu-se nas atividades desenvolvidas na oficina e nas falas dos participantes que "[.. ] o aprendizado deve ser um processo ativo, em que os aprendizes colocam a "mão na massa" (hands on) no desenvolvimento de projetos, ao invés de ficarem sentados atentos a fala do professor” (Maltempi, 2004, p.265). Sob esta ótica, o grupo 2 reforça que utilizaria esta metodologia em sala de aula. Para isso, iniciaria o processo de produção de um recurso, juntamente com a exploração da linguagem de programação do Scratch. possibilitando que os discentes levantassem dúvidas e dificuldades durante $\mathrm{o}$ desenvolvimento da proposta.

Nessa perspectiva, é importante considerar que para Papert (2008) o aprendizado acontece quando o aluno constrói um objeto de seu interesse, como um jogo, um vídeo, ou um desenho, e desta forma se permite adentrar em um processo de aprendizagem que permite a construção de conhecimentos.

Sobre o pensamento de construir, um participante relatou: “[...] sempre tive a curiosidade de construir programas de acordo com as necessidades dos estudantes. Penso que o diferencial do Scratch é exatamente estimular a criação e a autonomia dos usuários seja ele educadores ou estudantes.” Este extrato revela a importância de instrumentalizar o professor, dando-o a possibilidade de exercer sua autonomia, ao desenvolver seu próprio material didático. Ainda sobre esse olhar, Bressam e Amaral (2015) afirmam que a aprendizagem requer um processo que intercale situações de construção, reconstrução e constatação. Vale ressaltar a necessidade do desenvolvimento de atividades durante a formação docente que incentive os professores a refletir sobre o uso de TDIC e à incorporá-las em sala de aula, resultando em novas práticas rumo à construção do conhecimento, pois essas atividades apresentam "contribuições para a compreensão conceitual, teórica e metodológica da matemática” (Leitão; Castro, 2018, p.513).

Isto fica evidente, pois, durante a elaboração da proposta, os participantes precisaram definir conteúdos a serem trabalhados, assim como abordagens metodológicas. Ao programar seu próprio RED os participantes tiveram que ter consciência dos conceitos matemáticos trabalhados. A oficina oportunizou a exploração das competências 4 e 5 apontadas pela BNCC, em que uma apresenta a importância da utilização de diversas linguagens, inclusive a digital, ao possibilitar aos participantes vivências de aprendizagem em programar por meio do Scratch, e a outra, inserindo a cultura digital nas escolas, fazendo com que os professores e alunos consigam compreender o valor de utilizar e/ou criar TDIC, como possibilidade de produzir informação e conhecimento, resolver problemas e exercer protagonismo e autoria (Brasil, 2017).

Observa-se que mediante oficina, os participantes puderam desenvolver o pensamento computacional, visto que ao serem indagados com um problema específico, 
como desenvolver RED com o Scratch para o ensino de Matemática, precisaram utilizar ferramentas e habilidades computacionais, tendo que desenvolver um passo-a-passo para a criação do RED, a fim de solucionar a problemática de resoluções de questões e construção do conhecimento, apresentando no final da oficina, um recurso cuja finalidade é aumentar o poder cognitivo e operacional do educando.

Essa proposta de resolução de problemas por meio do desenvolvimento do pensamento computacional pode ser verificada em todas as criações produzidas. Destacase a proposta desenvolvida pelo grupo 3, Uma aventura com Naruto: aprendendo com Rãmen, que apresentou como problemática inicial a seguinte questão: "como trabalhar o processo de contagem com uma turma de primeiro ano, de uma maneira que permita um interesse do público e gere aprendizagem?" Ambas participantes estavam envolvidas na realização de um projeto interdisciplinar para alunos do primeiro ano e haviam aplicado um teste diagnóstico com as crianças. Assim, surgiu a escolha da temática no contexto do anime Naruto, na qual utilizaram suas experiências com estes alunos para propor as atividades e os desafios do RED.

As participantes compartilharam como expectativas para a oficina: compreender a lógica de programação da ferramenta com o objetivo de aprofundar esses conhecimentos futuramente. Desta forma, decidiram criar um RED que abordasse a proposta de contagem, explorando a ideia de quantidade de um número com imagens. Sendo assim, puderam utilizar conjuntos de instruções e de habilidades para conseguir uma solução computacional para a problemática apresentada, como mostra a figura 1.

Figura 1 - RED Uma aventura com Naruto aprendendo com Rãmen

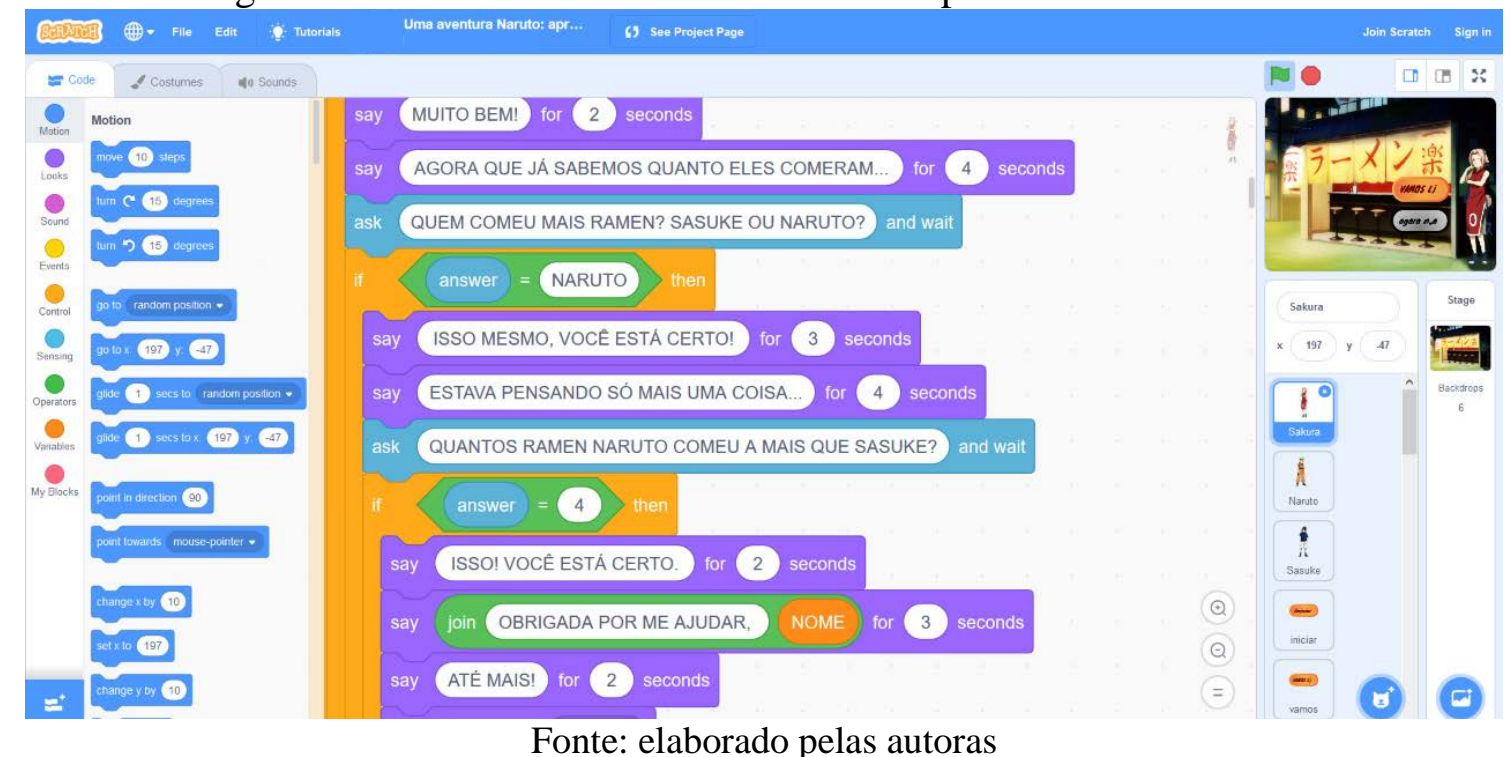

Diante da apresentação da dupla, o grupo compartilhou as suas percepções. O contexto utilizado foi algo pontuado pelo grupo como uma estratégia interessante. Visto que a narrativa abordada no RED, segundo as participantes, foi pensada de acordo com os interesses do público alvo, e que pôde ser observado a partir de uma pesquisa prévia realizada pela dupla com a turma para a qual o RED estava sendo desenvolvido.

Entende-se que o uso de situações que podem ser significativas para o público alvo, pode fornecer um bom incentivo para que o usuário tenha a sua concentração voltada para a resolução dos desafios apresentados no RED (Leitão; Castro, 2018).

Nesse sentido, Papert (2008) afirma que um dos maiores desafios da Educação está relacionado com a formação de sujeitos reflexivos e ao mesmo tempo, construtores de seus próprios artefatos. 
Desta forma, observou-se, a partir da avaliação final, que os participantes da oficina, enquanto estudantes em formação ou professores atuantes nas escolas, perceberam a importância de permanecerem em constante formação, necessitando de estímulos que lhe permitam assumir novas posturas diante das necessidades presentes na atualidade.

\section{CONSIDERAÇÕES FINAIS}

Como o processo de produção de mídias pode contribuir para a formação docente? Esta foi a questão que permeou as discussões levantadas neste artigo. Destacam-se como contribuições advindas do processo vivenciado em uma oficina e analisado por esta pesquisa: à apropriação tecnológica que contribuiu para o letramento digital de alguns participantes; o desenvolvimento do pensamento computacional, a partir da instrumentalização do Scratch para a produção de RED; a percepção do processo vivenciado como uma metodologia que poderia ser desenvolvida na escola; assim como, o empoderamento dado ao professor que vislumbrou a autoria como a possibilidade de construir seus próprios Recursos Educacionais Digitais.

A apresentação de uma linguagem de programação mais acessível contribuiu para que esses professores pudessem usá-la em questões de ensino, ao produzir seu próprio material, e em questões de aprendizagem.

Como foi pontuado ao longo do artigo, o Scratch foi utilizado para desenvolver aprendizagens de conceitos, teorias e metodologias para o ensino de matemática. Os participantes criaram; compartilharam em grupo os seus saberes; construíram colaborativamente novas aprendizagens; resolvendo problemas, seguindo o que é proposto pelo pensamento computacional.

Cabe ao professor agregar em sua metodologia, estratégias didáticas desafiadoras e que enriqueçam o processo de ensino e de aprendizagem de conceitos. Desta forma, o referencial teórico aponta para as contribuições que as TDIC podem trazer, expondo a importância que uma formação docente focada na prática profissional, propiciando aos futuros docentes o uso das tecnologias digitais como abordagem metodológica.

Entende-se que este estudo não deva ser finalizado aqui, pois a partir dele verificou-se a importância de levantar novas reflexões sobre práticas utilizando as tecnologias digitais e explorando o pensamento computacional, temas de grande interesse no momento atual. Pesquisas futuras precisam considerar a utilização de outras ferramentas, assim como, mapear conceitos desenvolvidos. Espera-se que outras questões possam ser abordadas e discutidas com novos olhares sobre esse tema, trazendo novas contribuições ao processo de ensino e de aprendizado de diferentes áreas do conhecimento.

\section{REFERÊNCIAS}

ARRUDA, J. S.; CASTRO-FILHO, J. A. de C. Tecnologias digitais e a aprendizagem: perspectivas para emergência de zonas de desenvolvimento proximal. Revista Novas Tecnologias na Educação. 2018. Disponível em: <https://seer.ufrgs.br/renote/article/view/89265> Acesso em: 02 Maio 2019

BRASIL, Ministério da Educação. Base Nacional Comum Curricular. Brasília: MEC/ Secretaria de Educação Fundamental. 2017

BRACKMANN, C. P. Desenvolvimento do pensamento computacional através de atividades desplugadas na educação básica. TESE. Universidade Federal do Rio Grande do Sul. Centro de Estudos Interdisciplinares em Novas Tecnologias da 
Educação. Programa de Pós-Graduação em Informática na Educação. 2017. Disponível em: <https://www.lume.ufrgs.br/handle/10183/172208> . Acesso em: 19 Maio 2019.

BRESSAN, M. L. Q.; AMARAL, M. A. Avaliando a Contribuição do Scratch para a aprendizagem pela solução de problemas e o desenvolvimento do Pensamento Criativo. Revista Intersaberes, vol.10, n.21, p. 509-526, 2015. Disponível em: $<$ https://www.uninter.com/intersaberes/index.php/revista/article/view/866/502>. Acesso em: 14 Abr. 2019

BRENNAN, K.; RESNICK, M. New frameworks for studying and assessing the development of computational thinking. AERA 2012, Vancouver, Canadá, 2012. Disponível em: $\quad$ https://web.media.mit.edu/ kbrennan/files/Brennan_Resnick AERA2012_CT.pdf.>. Acesso em: 19 Maio 2019.

BRITO. G. da S.; PURIFICAÇÃO, I. Educação e Novas Tecnologias: um repensar. São Paulo: Pearson, 2012.

CASTRO, J. B.; SOARES, I. O.; VIANNA, E. P. N.; SOUSA, J. S. Lógica Criativa: a construção de mídias digitais para o ensino de matemática. In: Anais dos Workshops do VI Congresso Brasileiro de Informática na Educação (WCBIE 2017). Disponível em: <http://www.br-ie.org/pub/index.php/wcbie/article/view/7431/5227>. Acesso em: 23 Mar. 2019

CHIAVENATO, I. Introdução à teoria geral da administração. 9.ed. Barueri: Manole, 2014.

DEMO, Pedro. Aprender como autor. São Paulo: Atlas, 2015.

GARCIA, M. F. G.; RABELO, D. F.; SILVA, D. da.; AMARAL, S. F. do. Novas competências docentes frente às Tecnologias Digitais Interativas. Revista Teoria e Prática da Educação, v.14, n.1, p. 70-87, jan./abril 2011. Disponível em: $<$ http://periodicos.uem.br/ojs/index.php/TeorPratEduc/article/view/16108/8715> Acesso em 10 Maio. 2019.

KENSKI, V. M. Educação e Tecnologias: o novo ritmo da informação. 8. ed. Campinas (SP): Papirus, 2012.

LEITÃO, D. A.; CASTRO, J. B. de.; A Construção de Recursos Digitais de Matemática: uma experiência de autoria com o Scratch. Anais dos Workshops do Congresso Brasileiro de Informática na Educação 2018. Disponível em: $<$ http://www.br-ie.org/pub/index.php/wcbie/article/view/8276> Acesso em: 01 Dez. 2018

MALTEMPI, M. V. Construcionismo: pano de fundo para pesquisas em informática. In: BICUDO, Maria Aparecida Viggiani; BORBA, Marcelo de Carvalho (Org.). Educação Matemática: pesquisa em movimento. São Paulo: Cortez, 2004. p.264-282.

PAPERT S. Mindstorms. Children, Computers and Powerful Ideas. New York: Basic books, 1980.

PAPERT, S. A máquina das crianças: repensando a escola na era da informática. Trad. Sandra Costa. Ed. revisada. Porto Alegre: Artmed, 2008.

VALENTE, J. A. Integração do Pensamento Computacional no currículo da Educação Básica: diferentes estratégias usadas e questões de formação de professores e avaliação do aluno. In Programa de Pós-Graduação em Educação: Currículo, 2016. 